\section{Prescribing ECT: do psychiatrists behave oddly?}

Sir: In the treatment of depression with electroconvulsive therapy (ECT), there was in the past controversy about the number of applications needed to give maximum benefit. Six seemed a popular number. However, Barton et al (1973) showed that once clinical recovery had occurred, treatment should be stopped. Thus there is no reason to suppose that a patient would be more likely to respond to an even number of applications than to an odd number. Likewise, if a patient failed to respond to ECT, it would seem illogical to abandon ECT after an even rather than an odd number of applications. However, we had a clinical impression that even numbers of applications were prescribed more often than odd numbers. We therefore obtained prescription records for courses of ECT from 1 May 1991 to 31 April 1992 from one Glasgow hospital, and counted the frequencies of different numbers of applications.

A total of 103 courses of ECT was prescribed over the period of study: courses varied from one to 17 applications. The numbers of applications and (in brackets) the frequency at which they were prescribed, were as follows: $1(3), 2(6), 3(9)$, 4 (15), $5(8), 6(27), 7(5), 8$ (17), $9(5), 10$ (5), 11 $(1), 12(0), 13(1), 14(0), 15(0)$, and $17(1)$. Thus there were 70 'even' but only 33 'odd' courses of ECT (binomial $P<0.001$, one-tailed).

We are tempted to speculate that in showing a preference for even numbers, psychiatrists are superstitious, obsessional or both! Indeed the Royal College of Psychiatrists encourages such neurotic behaviour in its official video on ECT, in which a patient is seen being told to expect six or eight applications. A more mundane explanation may lie in the College booklet on ECT (1989), which recommends that no more than two applications be prescribed at one time. Ideally, the patient would be assessed after every application. However, the psychiatrist with a heavy workload might well prescribe two applications at a time with a consequent bias towards even numbers.

It seems likely that in the case of a patient for whom the optimal number of applications was odd, the psychiatrist would round up to an even number rather than stop at one application short of recovery. Thus some patients would get one application too many. While the anaesthetic risk from ECT is small, it should not be ignored and there is also the time and cost of extra anaesthesia. We therefore recommend that psychiatrists examine their prescribing practice since some may need encouragement to behave oddly.

BARTON, J.L., MEHTA, S. \& SNATH, R.P. (1973) The prophylactics value of extra ECT in depressive lliness. Acta Psychiatrica Scandinavica, 49, 386-392.
Royal CoLlege of PSychlatrists (1989) The Practical Administration of Electroconvulstue Therapy. London: Gaskell (Royal College of Psychiatrists).

A.V. MARK HUGHSON and DONALD LYONS, Leverndale Hospital, Glasgow G53 7TU

\section{Consent or no consent}

Sir: A 36-year-old caucasian male with a 20 year history of schizophrenia was admitted in a catatonic state having refused to eat or drink for some days. He later explained that he "had run out" of risperidone tablets one week earlier. He had presented in a similar way on previous occasions when he responded dramatically to one application of electroconvulsive therapy, usually requiring three to four treatments to gain maximum response.

In view of his physical condition on arrival, his favourable response to ECT in the past and the approval of his nearest relative, he was given a single emergency treatment. He responded as anticipated and signed a consent form for further electroconvulsive treatments.

Some hours later he informed his psychiatrist that he did not feel the consent was valid and would have to withdraw it. He explained that, although he consented to further therapy, he believed he had only signed the form under the influence of Satan and that it was Satan and not he who had signed. He endeavoured to sign another form but did not believe he was signing under his own volition. He was happy to give verbal consent and did so in front of a witness. Two further treatments were given and he was discharged much improved (with an ample supply of risperidone) one week after admission.

The patient made it clear that he understood the nature of the treatment offered and potential dangers, that he agreed to and indeed wanted to be treated and that he did not wish to be detained under a section of the Mental Health Act. Due to his delusion, however, he felt that he could not give valid written consent although he was happy to give oral consent in front of a witness.

In these circumstances is oral consent acceptable?

ALFRED C. WHITE, Queen Elizabeth Psychtatric Hospital, Edgbaston, Birmingham B15 2QZ

\section{Mental disorder and driving}

Sir: Lawrie \& Milne have provided a useful overview and sensible reminder to doctors concerning the effects of mental illness and psychotropic treatments on driving (Psychiatric Bulletin, April 1994, 18, 214-216). We had also been struck by the implications of the Driver and Vehicle Licensing Agency's recent guide (DVLA, 1993), in 